\title{
Yes, not now, or never: an analysis of reasons for refusing or accepting emergency department-based take-home naloxone
}

Andrew Kestler, MD, MBA, MScPH ${ }^{*}$; Amanda Giesler, MHA ${ }^{\ddagger}$; Jane Buxton, MBBS, MHSc ${ }^{\ddagger \S}$; Gray Meckling, BSc ${ }^{\pi}$; Michelle Lee, BSc, MPH, MD"; Garth Hunte, MD, $\mathrm{PhD}^{*}{ }^{\dagger}$; Jacob Wilkins, $\mathrm{MD}^{\dagger}$; Dalya Marks, $\mathrm{PhD}^{* *}$; Frank Scheuermeyer, MD, MHSc ${ }^{*}$

\author{
CLINICIAN'S CAPSULE \\ What is known about the topic? \\ Not all patients at risk of opioid overdose accept emergency \\ department (ED)-based take-home naloxone (THN). \\ What did this study ask? \\ Why do at-risk ED patients refuse or accept THN? \\ What did this study find? \\ Those refusing THN felt: 1) not at risk of overdose; or 2) their \\ ED visit was not the right time or place for THN. Those \\ accepting THN wanted to save the lives of others. \\ Why does this study matter to clinicians? \\ Those refusing ED THN may accept THN elsewhere if \\ referred to appropriate community services for overdose \\ risk education and THN distribution.
}

\section{ABSTRACT}

Objective: Take-home naloxone (THN) reduces deaths from opioid overdose. To increase THN distribution to at-risk emergency department (ED) patients, we explored reasons for patients' refusing or accepting THN.

Methods: In an urban teaching hospital ED, we identified high opioid overdose risk patients according to pre-specified criteria. We offered eligible patients THN and participation in researcher-administered surveys, which inquired about reasons to refuse or accept THN and about THN dispensing location preferences. We analyzed refusal and acceptance reasons in open-ended responses, grouped reasons into categories (absolute versus conditional refusals,) then searched for associations between patient characteristics and reasons.

Results: Of 247 patients offered THN, 193 (78.1\%) provided reasons for their decision. Of those included, 69 (35.2\%) were female, 91 (47.2\%) were under age 40, 61 (31.6\%) were homeless, 144 (74.6\%) reported injection drug use (IDU), and $131(67.9 \%)$ accepted THN. Of 62 patients refusing THN, 19 $(30.7 \%)$ felt "not at risk" for overdose, while 28 (45.2\%) gave conditional refusal reasons: "too sick," "in a rush," or preference to get THN elsewhere. Non-IDU was associated with stating "not at risk," while IDU, homelessness, and age under 40 were associated with conditional refusals. Among acceptances, $86(65.7 \%)$ mentioned saving others as a reason. Most respondents preferred other dispensing locations beside the ED, whether or not they accepted ED THN.

Conclusion: ED patients refusing THN felt "not at risk" for overdose or felt their ED visit was not the right time or place for THN. Most accepting THN wanted to save others.

\section{RÉSUMÉ}

Objectif: L'utilisation de la naloxone à domicile (ND) permet de diminuer la mortalité liée aux surdoses d'opioïdes. L'étude visait donc, dans le contexte d'une distribution accrue de ND parmi les patients à risque traités au service des urgences (SU), à examiner les motifs de refus ou d'acceptation de I'offre d'utilisation extrahospitalière de l'antidote.

Méthode: Les patients traités dans un SU d'un hôpital d'enseignement situé en milieu urbain et connaissant un risque élevé de surdoses d'opioïdes ont fait l'objet d'une sélection selon des critères prédéterminés. Les patients admissibles se sont vu offrir de la ND et la possibilité de participer à une enquête menée par des chercheurs, sur les motifs de refus ou d'acceptation de la ND et sur les préférences quant aux lieux de distribution de la ND. Après la collecte des réponses aux questions ouvertes, il y a eu analyse des motifs de refus ou d'acceptation, catégorisation des motifs (refus absolus ou conditionnels) et recherche d'associations entre les motifs et les caractéristiques des patients.

From the *Department of Emergency Medicine, St. Paul's Hospital, Vancouver, BC; †Department of Emergency Medicine, University of British Columbia, Vancouver, BC; $¥$ School of Population and Public Health, University of British Columbia, Vancouver, BC; §British Columbia Centre for Disease Control, Vancouver, BC; IFaculty of Science, University of British Columbia, Vancouver, BC; IFaculty of Medicine, University of British Columbia, Vancouver, BC; and the **London School of Hygiene \& Tropical Medicine, London, UK.

Correspondence to: Dr. Andrew Kestler, Department of Emergency Medicine, University of British Columbia \& St Paul's Hospital, 1081 Burrard St, Vancouver, BC V6Z 1Y6, Canada; Email: andrew.kestler@ubc.ca 
Résultats: Sur 247 patients qui se sont vu offrir de la ND, 193 $(78,1 \%)$ ont fourni leurs motifs de décision. Parmi les sujets retenus, il y en avait 69 (35,2\%) qui étaient des femmes, 91 $(47,2 \%)$ qui étaient âgés de moins de 40 ans, 61 (31,6\%) qui étaient des sans-abris, $144(74,6 \%)$ qui faisaient usage de drogues injectables (UDI) et $131(67,9 \%)$ qui ont accepté l'offre de ND. Sur les 62 patients qui ont refusé I'offre de ND en cas de surdose, $19(30,7 \%)$ se considéraient comme " non à risque " et $28(45,2 \%)$ autres ont invoqué des motifs conditionnels de refus : " trop malades ", " trop pressés " ou autre lieu de distribution de la ND. Le non-UDI était associé à l'énoncé " non à risque ", tandis que I'UDI, le sans-abrisme et un âge inférieur à 40 ans étaient associés à des refus conditionnels. Parmi les patients qui ont accepté l'offre, 86
$(65,7 \%)$ ont indiqué, comme motif, le fait de sauver la vie d'autres personnes. La plupart des répondants préféraient d'autres lieux de distribution au SU, quelle que soit leur réponse à l'offre de ND.

Conclusions: Les patients au SU qui ont refusé I'offre de ND en cas de surdose se considéraient comme "non à risque " ou estimaient que ce n'était pas le bon moment ou la bonne place pour discuter de la ND. La plupart de ceux qui ont accepté l'offre de ND voulaient sauver la vie d'autres personnes.

Keywords: take-home naloxone, opioid overdose, emergency department

\section{INTRODUCTION}

In 2016, an unprecedented 2,800 Canadians died of an opioid overdose (OD), ${ }^{1}$ while the hospitalization rates and emergency department (ED) visits for opioid OD have increased correspondingly. ${ }^{2}$ Take-home naloxone (THN), consisting of several doses of naloxone, singleuse instructions, simple rescue breathing masks, and educational brochures, is a harm reduction intervention for bystander opioid OD reversal. Dispensing THN to at-risk users has reversed over 26,000 ODs in the United States $^{3}$ and decreased opioid-related community death rates. ${ }^{4}$ Seven of the 13 Canadian provinces and territories have initiatives to expand THN access and coverage. $^{2,5}$

As ED visits and non-fatal ODs are markers for subsequent OD mortality, ${ }^{3,6,7}$ EDs become an opportune setting to reach those at highest risk. In North America, EDs increasingly dispense $\mathrm{THN}^{8-13}$ and $70 \%$ of ED patients accept THN. ${ }^{8}$ While physician barriers to ED-based THN dispensation have been reported, ${ }^{9,12,14}$ patient-specific reasons for ED THN acceptance or refusal have not. In non-ED settings, factors contributing to refusals include the reluctance to administer injections, fear of triggering additional drug use, and inappropriate minimization of OD risk. ${ }^{15-19}$ Conversely, patients are motivated to accept THN if they feel they can help others, ${ }^{17,19,20}$ if they have had an OD themselves, ${ }^{18}$ or if they know a peer with THN. ${ }^{21}$

To improve the quality and reach of ED THN distribution and education, it is crucial to gain a greater understanding of the reasons influencing THN refusal or acceptance for ED patients. We surveyed high-risk ED patients to explore reasons for refusing or accepting THN.

\section{METHODS}

\section{Design and philosophy}

The study was a content analysis of open-ended question responses in a researcher-administered survey of ED patients with both qualitative and quantitative aspects. Quantitative analysis of other survey questions has been previously reported. ${ }^{8}$ Descriptive qualitative tools borrowed from grounded theory informed the analysis of open-ended responses, allowing themes to emerge from the respondents' own words. ${ }^{22}$ Because use of qualitative tools confers some of the risks and benefits of qualitative research, we will report the methods and results according to the Standards for Reporting Qualitative Research (SRQR) format. ${ }^{23}$ Our research philosophy is consistent with post-positivism or pragmatism, ${ }^{24,25}$ for which we acknowledge and address the subjectivity of the research team. Our design was dictated by the practical need for the THN program implementers to quickly solicit "real-world" (during an actual ED visit rather than a planned focus group) patient input that could be used for program evaluation and improvement. Because of time and space constraints of approaching candidates during their ED stay, the survey adopted sampling and analysis strategies that were predetermined and not iterative. For similar reasons, the survey did not contain follow-up questions to open-ended responses. As most open-ended responses were short, a count-based quantitative approach supplemented the use of qualitative tools. To facilitate this quantitative analysis, consensus building and inter-coder agreement were deemed desirable (contrary to qualitative approaches in which presenting interpretive disagreements between researchers might 
enhance the analysis). Finally, we included some quantitative analysis of previously unreported data from closedended questions on feeling respected in the ED and preferred locations for THN dispensing, as we felt these data were complimentary to the open-ended questions.

\section{Context}

The study took place at St. Paul's Hospital ED in Vancouver, British Columbia. Many of the 85,000 annual patients have unstable housing, mental illnesses, and substance use disorders including injection drug use (IDU). The province of British Columbia is home to the first officially sanctioned supervised drug injection site in North America ${ }^{26}$ and first provincial THN program in Canada. ${ }^{19}$ Shortly before the study, the ED became an approved dispensing site for the provincial THN program; ED staff offered THN to at-risk patients and provided standardized THN training lasting approximately five minutes. During the study, research assistants (RAs) offered eligible patients THN (as part of the provincial program) and survey participation simultaneously. RAs were non-physicians who had no direct patient care involvement. All RAs had an ED orientation, an introduction to harm reduction principles, and an opportunity to pilot the study before beginning study work. Regular ED staff continued to train patients and dispense THN to those interested, regardless of study participation.

\section{Sampling strategy}

RAs screened candidates using triage notes and printouts for the last six months from the provincial pharmacy database. The following patients were approached: 1) self-reported opioid use at triage or during pre-hospital care; 2) clinical opioid OD or withdrawal; 3) prescriptions of methadone, buprenorphine/naloxone, or other opioids exceeding 100 morphine equivalents daily; 4) injectionrelated infections; and 5) narcotic requests (defined as the chief complaint, including a request for a refill of a previous opioid prescription). ED staff could refer additional study candidates to the RAs. RAs invited consecutive eligible patients to participate and excluded patients too ill, agitated, or sedated to answer study questions or undergo THN training. Those who already had a THN kit were ineligible. The rationale for selecting a target sample size of 200 was based on the previously reported quantitative outcome-based component of the study. ${ }^{8}$

\section{Ethics, consent, and permissions}

All participants provided written informed consent, could choose a suitably private ED interview location, and could receive THN regardless of survey participation. Age range and gender, as well as eligibility criteria that were met, were recorded without personal identifiers for study candidates who declined participation or who met the exclusion criteria. The University of BritishColumbia-Providence Health Care Research Ethics Board (H14-03430) and the London School of Hygiene \& Tropical Medicine (MSc Ethics 8673) approved the study.

\section{Data collection}

RAs covered pre-specified four- to eight-hour shifts in a 2:1 daytime to evening ratio including weekends from May to August 2015 and administered the survey (see Online Appendix $)^{8}$ to consenting patients after medical stabilization. RAs asked patients about demographics, substance use, and THN-related preferences, as well as an open-ended question on the reason for accepting or refusing THN. Participants who had difficulty answering open-ended questions were provided with "prompts," a menu of possible answers (see Online Appendix) containing themes previously cited in the harm reduction literature and by content experts including patients and addiction specialists. Patients completing the standardized 15-20 minute survey received $\$ 10$ compensation. RAs entered verbatim (in the patient's voice) responses into anonymous electronic survey forms (Surveymonkey.com, Palo Alto, CA). Responses were later transferred to Excel (version 14.7.1; Microsoft, Redmond, WA) and STATA (version 11.0; StatCorp, College Station, TX) for further analysis. During data collection, RAs regularly communicated with each other and the study leads to clarify uncertain points or conflicting data.

\section{Data analysis}

We analyzed open-ended question responses by developing a coding structure for reasons to accept or reject THN. The primary coder was an RA who analyzed the open-ended responses as part of her master's thesis. The primary coder and one senior researcher initially independently coded the same random 20\% subset of responses and then met to 
discuss their coding structure with a qualitative research methodologist to generate a consensus for a codebook. The primary coder applied the codebook to the complete data set, adding additional codes, as needed. A secondary coder not involved in the initial coding or interviews analyzed the data using the codebook. The two coders' selections were compared for inter-coder reliability, with full code matching required if a response had more than one code assigned. A discussion between coders, moderated by a senior researcher, generated further consensus, leading to a measure of inter-coder agreement. ${ }^{27}$ If any disagreement between coders persisted, the senior moderator's chosen code was used for further analysis. ${ }^{27}$ To test associations of patient characteristics with specific reasons for THN acceptance or refusal, we classified characteristics by the following pre-specified mutually exclusive subgroups: male/female, IDU/non-IDU, no fixed address (homeless)/fixed address, and older than 40/younger than 40 . Reasons mentioned in $10 \%$ or more of the refusals or acceptances were tested for their association with the patient characteristics. To facilitate some quantitative analysis of the reasons mentioned by fewer than $10 \%$ of the respondents, we included these responses into larger, mutually exclusive, and binary category groupings by identifying overarching themes. We tested these categories for their association with the patient characteristics. Reasons for THN refusal were classified into the categories, absolute (not interested in THN at all) or conditional (potentially interested in THN but not desiring it during this ED visit). Reasons for THN acceptance were classified into the following categories: either mentioning a desire to help others or not mentioning this desire. To test for potential confounding, patient characteristics were checked for association with other patient characteristics. We used Fisher's exact test for testing all associations, with a $p$ equal to 0.05 as a threshold for significance. Responses to closed-ended questions on feeling respected in the ED and THN preferences were analyzed using descriptive statistics only.

\section{RESULTS}

We identified 417 consecutive THN candidates and offered 247 eligible patients THN and survey participation, of whom 193 (78.1\%) completed the open-ended questions on THN acceptance and were analyzed (Figure 1). Participant characteristics, as well as those of patients who were excluded or refused to participate, are shown in Table 1. Interviewers used at least one prompt for approximately one-quarter of the patients. The coding process identified 10 reasons for refusal and 12 reasons for acceptance that were grouped into mutually exclusive binary response categories (Table 2). Associations between patient characteristics and types of responses are presented in Table 3. Intercoder reliability was $74.9 \%$ (95\% confidence interval [CI] $68.7-81.0 \%, N=191$ because two originally misclassified responses were not included in the calculation), and inter-coder agreement after discussion was 95.3\% (95\% CI $92.3-98.3 \%, N=191$ as above).

\section{Reasons for refusing THN}

Sixty-two patients provided reasons for refusing THN (Table 3 for all results below unless otherwise mentioned). "I'm not at risk" was the most common, mentioned by $30.7 \%$ (95\% CI $19.2-42.2 \%$ ) of the patients refusing. IDU patients expressed this reason

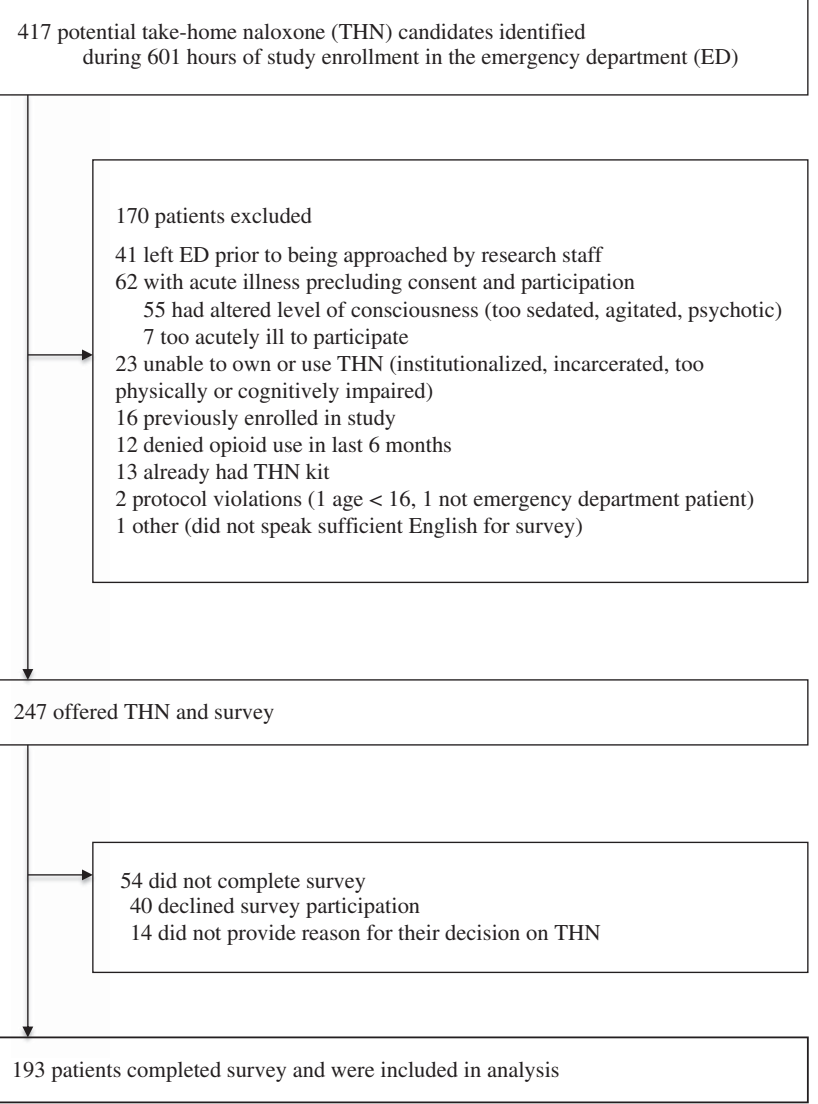

Figure 1. Study flow diagram. 


\begin{tabular}{|c|c|c|c|c|c|c|c|}
\hline \multirow[b]{2}{*}{ Characteristic } & \multicolumn{2}{|c|}{$\begin{array}{l}\text { Included } \\
N=193\end{array}$} & \multicolumn{2}{|c|}{$\begin{array}{l}\text { Declined } \\
N=54\end{array}$} & \multicolumn{2}{|c|}{$\begin{array}{c}\text { Excluded } \\
N=170\end{array}$} & \multirow[b]{2}{*}{ Fisher's exact ${ }^{*}$} \\
\hline & $n(\%)$ & $95 \% \mathrm{Cl}$ & $n(\%)$ & $95 \% \mathrm{Cl}$ & $n(\%)$ & $95 \% \mathrm{Cl}$ & \\
\hline \multicolumn{8}{|l|}{ Demographics } \\
\hline Female & 69 (35.2) & $28.6-42.2$ & $22(40.7)$ & $27.2-54.3$ & $66(38.8)$ & $31.4-46.2$ & \\
\hline Under age 40 years & $91(47.2)$ & $40.0-54.3$ & $20(37.0)$ & $24.1-49.9$ & $84(49.4)$ & $41.9-56.9$ & \\
\hline Indigenous & $47(24.7)$ & $18.5-30.9$ & - & - & - & - & \\
\hline Homeless & $61(31.6)$ & $25.0-38.2$ & - & - & - & - & \\
\hline \multicolumn{8}{|l|}{ Opioid use } \\
\hline$I D U^{*}$ & $144(74.6)$ & $68.4-80.8$ & - & - & - & - & \\
\hline IDU from triage screening $^{\dagger}$ & $85(44.0)$ & $37.0-51.1$ & $24(44.4)$ & $30.8-58.1$ & $75(44.1)$ & $36.6-51.7$ & \\
\hline Methadone or suboxone prescription & 86144.6 & $37.5-51.6$ & $25(46.3)$ & $32.6-60.0$ & $70(41.2)$ & $33.8-48.9$ & \\
\hline High-dose opioid analgesic prescription ${ }^{\ddagger}$ & $31(16.1)$ & $10.8-21.3$ & $8(14.8)$ & $5.0-24.6$ & $13(7.6)$ & $3.6-11.7$ & $p=0.040$ \\
\hline \multicolumn{8}{|l|}{ ED presentation } \\
\hline Opioid overdose & $29(15.0)$ & $9.9-20.1$ & $16(29.6)$ & $17.0-42.2$ & $36(21.2)$ & $15.0-27.4$ & $p=0.043$ \\
\hline Other opioid-related chief complaints ${ }^{\S}$ & $58(30.1)$ & $23.5-36.6$ & $12(22.2)$ & $10.8-33.7$ & $38(22.4)$ & $16.0-28.7$ & \\
\hline Non-opioid-related chief complaints & $106(54.9)$ & $47.8-62.0$ & $26(48.1)$ & $34.4-61.9$ & $96(56.5)$ & $48.9-64.0$ & \\
\hline \multicolumn{8}{|l|}{ Outcome } \\
\hline Take-home naloxone acceptance & $131(67.9)$ & $61.2-74.5$ & $-\pi$ & - & - & - & - \\
\hline \multicolumn{8}{|l|}{ ED respect and THN location preferences } \\
\hline Does not always feel respected in ED & $73(36.8)$ & $29.9-43.7$ & - & - & - & - & - \\
\hline Prefers THN dispensing location other than ED" & $117(75.5)$ & $68.6-82.3$ & - & - & - & - & - \\
\hline $\begin{array}{l}\mathrm{Cl}=\text { confidence interval; } \mathrm{ED}=\text { emergency department; IDU = injecti } \\
\text { "Difference among the three groups significant at a 95\% level usin } \\
+ \text { "IDU from triage screening" refers to IDU reported in triage docur } \\
\text { "Prescription data obtained from print-out report of the last six mon } \\
\text { "Other opioid-related chief complaints included soft-tissue infection } \\
\text { "- data unavailable for patients refusing or excluded. } \\
\text { " } n=155\end{array}$ & $\begin{array}{l}\text { n drug use; THN } \\
\text { g Fisher's exact } \\
\text { nents only. } \\
\text { ths from the pro } \\
\text { consistent with }\end{array}$ & $\begin{array}{l}=\text { take-home nal } \\
\text { est. } \\
\text { incial pharmacy } \\
\text { DU, withdrawal, }\end{array}$ & $\begin{array}{l}\text { oxone. } \\
\text { database. } \\
\text { and opioid req }\end{array}$ & & & & \\
\hline
\end{tabular}

significantly less frequently than non-IDU patients. Some participants taking prescription opioids provided additional details regarding risk perception: "I'm just not interested. I don't believe I will truly OD because my doc has close eye on my meds." Other reasons for absolute refusals included "Encourages abuse," "Would not use," "Uncomfortable with injections," "Done with drugs," and passive suicidality (Table 2). When refusing THN, women endorsed "Done with drugs" three times as frequently as men that was a significant difference. Of 62 patients refusing THN, 28 (45.2\% [95\% CI $32.8-57.6 \%]$ ) endorsed the following conditional reasons: "Poor timing," "In a rush," "Too sick," and preference for another location. Patient characteristics significantly associated with conditional refusals were younger than 40 years, homelessness, and IDU status.

\section{Reasons for accepting THN}

"Save someone else's life" was the most common acceptance reason, mentioned by $65.6 \%$ (95\% CI $57.4-73.9 \%)$ of patients accepting THN, followed by "Save my own life" with $35.1 \%$ (95\% CI $26.8-43.4 \%$,), and $22.1 \%$ (95\% CI 15.0-29.2\%) of the patients stated both reasons. Aged less than 40 years was significantly associated with the "Save my own life" reason for accepting THN. One accepting patient also mentioned feelings of potential self-harm: "Because I've thought about suicide by an overdose so it would be safe to have one around in case I change my mind." The acceptance category "for self," encompassing all acceptance responses not specifically mentioning the desire to help others, was not associated with any particular patient characteristic (Table 3).

\section{Preference for other THN distribution locations and feeling respected}

Overall, 155 patients (including those refusing and accepting THN) answered a closed-ended question on THN location preference. Of these, 117 (75.5\% [95\% CI 68.6-82.3\%]) preferred non-ED sites. The supervised 


\begin{tabular}{|c|c|c|c|c|}
\hline Code & Reason & & $\begin{array}{l}\text { Frequency, } \\
n(\%)^{*}\end{array}$ & $\begin{array}{l}\text { Reason } \\
\text { Category }\end{array}$ \\
\hline & Refusing THN & Illustrative quotes & $62(100.0)$ & \\
\hline 8 & Not at risk & "I know my limit so I don't need a Narcan kit." & $19(30.7)$ & Absolute \\
\hline 2 & Done with drugs & $\begin{array}{l}\text { "Right now I'm going to detox and I don't need opioids or anything related } \\
\text { to opioids in my life anymore." }\end{array}$ & $11(17.7)$ & Absolute \\
\hline 3 & Too sick & $\begin{array}{l}\text { "I'm not in the best shape right now and I wouldn't want to miss anything } \\
\text { important in the training so I'll do it another day." }\end{array}$ & $11(17.7)$ & Conditional \\
\hline 6 & Prefers other location & "I can also get a kit from work or other places because I know where to go." & 9 (14.5) & Conditional \\
\hline 1 & In a rush & "I've been here a long time and I want to get going." & $6(9.7)$ & Conditional \\
\hline 4 & Poor timing & "I just got released from the hospital and it's not a good time to take one." & $6(9.7)$ & Conditional \\
\hline 9 & Would not use & "I am not around people who use drugs" & $5(8.1)$ & Absolute \\
\hline 5 & $\begin{array}{l}\text { Uncomfortable giving } \\
\text { injections }\end{array}$ & $\begin{array}{l}\text { "I wouldn't want to inject someone with a kit—not comfortable doing } \\
\text { that." }\end{array}$ & $2(3.2)$ & Absolute \\
\hline 7 & Encourages abuse & "I feel like these kits would be abused. Gives people an excuse to use more." & $2(3.2)$ & Absolute \\
\hline \multirow[t]{3}{*}{10} & Passive suicidality & "I just don't care." & $2(3.2)$ & Absolute \\
\hline & Conditional category & $\begin{array}{l}\text { Reason based on time and place, mutually exclusive of any response } \\
\text { mentioning absolute reason }\end{array}$ & $28(45.2)$ & \\
\hline & Accepting THN & Illustrative quotes & $131(100.0)$ & \\
\hline 2 & Save someone else's life & "My brother is at risk of dying of an overdose and I want to help him." & $86(65.7)$ & For others \\
\hline 3 & Save my own life & "So I don't overdose when I shoot up." & $46(35.1)$ & For self \\
\hline 1 & General safety & "Just in case. To be safe." "It's a good thing to have." & $20(15.3)$ & For self \\
\hline 8 & Willing to try & "Just to try it out." "Why not?" & $3(2.3)$ & For self \\
\hline 7 & $\begin{array}{l}\text { Did not know where to get } \\
\text { one }\end{array}$ & $\begin{array}{l}\text { "Always thought it would be a good idea to have one but I didn't know } \\
\text { where I could go to get one." }\end{array}$ & $1(0.8)$ & For self \\
\hline 4 & Never had one & "Never had one before and it would be good to have one around." ${ }^{\dagger}$ & $1(0.8)$ & For self \\
\hline 5 & Educate others & "Show people the kits and tell my friends they are available" & $1(0.8)$ & For others \\
\hline 6 & Lost other kit & "Lost my old one and want it just in case I overdose in the future." & $1(0.8)$ & For self \\
\hline 10 & $\begin{array}{l}\text { Supervised injection site } \\
\text { crowded }\end{array}$ & "Insite ${ }^{\S}$ is always busy so it would be a good thing to have around." & $1(0.8)$ & For self \\
\hline 9 & Peer impact & "Heard about it and saw someone with a kit." & $1(0.8)$ & For self \\
\hline 11 & Feels good & "Always like having one. Actually feels bad not having one." & $1(0.8)$ & For self \\
\hline \multirow[t]{2}{*}{12} & Everyone should have one & $\begin{array}{l}\text { "We should all have one. I want one because I need one and everyone } \\
\text { should carry it with them." }\end{array}$ & $1(0.8)$ & For self \\
\hline & For self category & $\begin{array}{l}\text { Reason not mentioning others, mutually exclusive of any response } \\
\text { mentioning desire to help others }\end{array}$ & 44 (33.6) & \\
\hline \multicolumn{5}{|c|}{$\begin{array}{l}\text { THN = take-home naloxone. } \\
\text { "Frequency sum is greater than } 100 \% \text { because some responses included more than one reason } \\
\text { "Response also counted as acceptance code } 1 . \\
\text { "Response also counted as acceptance code } 3 .\end{array}$} \\
\hline
\end{tabular}

injection site was the most frequently preferred location for THN distribution, followed by the ED, and, then, in descending order of preference, community clinics, family doctors, methadone doctors, pharmacies, and their own apartment buildings. THN location preference was not associated with specific open-ended response reasons for refusing or accepting THN, other than "Prefers other location." Nine patients expressed "Prefers other location" as a reason for refusal in open-ended responses, although only one mentioned a specific reason ("not a hospital fan"). Of the overall study cohort, $36.8 \%$ of the patients felt inadequately respected in the ED. This lack of respect was not significantly associated with a preference for a non-ED THN location, conditional refusals, or refusing THN overall.

\section{DISCUSSION}

In this survey of $193 \mathrm{ED}$ patients at risk of opioid overdose, we identified the key reasons for refusal and acceptance of THN. While understanding motivators 


\begin{tabular}{|c|c|c|c|c|c|c|c|c|}
\hline $\begin{array}{l}\text { Participants expressing reason according to } \\
\text { selected characteristics, } n(\%)\end{array}$ & Female & Male & IDU & No IDU & NFA & Not NFA & Age $\geq 40$ & Age $<40^{\dagger}$ \\
\hline Reasons for refusing THN & $N=16^{*}$ & $N=45^{*}$ & $N=38$ & $N=24$ & $N=18$ & $N=44$ & $N=33$ & $N=29$ \\
\hline Not at risk & $6(37.5)$ & $13(28.9)$ & $6(15.8)^{\ddagger}$ & $13(54.2)^{\ddagger}$ & $3(16.7)$ & $16(36.4)$ & $13(39.4)$ & $6(20.7)$ \\
\hline Done with drugs & $6(37.5)^{\ddagger}$ & $5(11.1)^{\ddagger}$ & $6(15.8)$ & $5(20.8)$ & $1(5.56)$ & $10(22.7)$ & 7 (21.2) & $4(13.8)$ \\
\hline Too sick & $3(18.8)$ & $7(15.6)$ & $7(18.4)$ & $4(16.7)$ & $4(22.2)$ & 7 (15.9) & $4(12.2)$ & $7(24.1)$ \\
\hline Prefers other location & $2(12.5)$ & 7 (15.6) & 7 (18.4) & $2(8.3)$ & $4(22.2)$ & $5(11.4)$ & $3(9.1)$ & $6(20.7)$ \\
\hline Conditional reason category & $6(37.5)$ & $21(46.7)$ & $22(57.9)^{\ddagger}$ & $6(25.0)^{\ddagger}$ & $12(66.7)^{\ddagger}$ & $16(36.4)^{\ddagger}$ & $10(30.3)^{\ddagger}$ & $18(62.1)^{\ddagger}$ \\
\hline Reasons for accepting $T H N^{\S}$ & $N=52$ & $N=79$ & $N=106$ & $N=25$ & $N=43$ & $N=88$ & $N=69$ & $N=62$ \\
\hline Save someone else's life & $34(65.4)$ & $52(65.8)$ & $70(66.0)$ & $16(64.0)$ & $26(60.5)$ & $60(68.2)$ & $46(66.7)$ & $40(64.5)$ \\
\hline Save my own life & $18(34.6)$ & $28(35.4)$ & $36(34.0)$ & $10(40.0)$ & $16(37.2)$ & $30(34.1)$ & $18(26.1)^{\ddagger}$ & $28(45.2)^{\ddagger}$ \\
\hline General safety & $9(17.3)$ & $11(13.9)$ & $17(16.0)$ & $3(12.0)$ & 7 (16.3) & $13(14.8)$ & $11(15.9)$ & 9 (14.5) \\
\hline For self reason category & $18(34.6)$ & $26(32.9)$ & $35(33.0)$ & $9(36.0)$ & $17(39.5)$ & $27(30.7)$ & $23(33.3)$ & $21(33.9)$ \\
\hline $\begin{array}{l}\text { IDU: Injection drug use; NFA: No fixed address (homeless } \\
\text { "One participant identifying as "other" gender was not in } \\
+ \text { Variables: age }<40 \text { years, IDU, and NFA were all associa } \\
{ }^{\ddagger} p<0.05 \text { using Fisher's exact test. } \\
{ }^{s} \text { Characteristics from Table } 1 \text { that were not associated with } \\
\text { analgesic prescription, and type of emergency departmen }\end{array}$ & $\begin{array}{l}\text { s) } \\
\text { cluded in the ar } \\
\text { ted with each } \\
\text { in specific reasor } \\
\text { th presentation. }\end{array}$ & $\begin{array}{l}\text { alysis. } \\
\text { ther using Fish }\end{array}$ & exact test ( $p$ & $<0.05)$ & 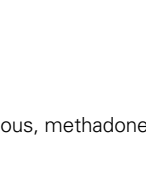 & 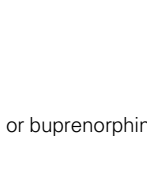 & . & -dose opioid \\
\hline
\end{tabular}

of THN acceptance is important, understanding barriers is critical; our findings may help physicians overcome the reluctance of vulnerable ED patients to accept a life-saving intervention.

The most common reason for refusal was feeling "not at risk" for OD. Some patients expressed confidence that they would not overdose if taking opioids only as prescribed by their physician, as previously noted in patients on opioids for chronic pain. ${ }^{19}$ Unfortunately, patients taking prescription opioids are at an increased overdose risk, proportional to increasing opioid doses. ${ }^{28}$ Conversely, our IDU patients less frequently mentioned "not at risk" as a reason for refusing THN, suggesting they might be more aware of overdose risk.

The reasons "done with drugs" and "encourages abuse" arose in our study population, mirroring concerns elsewhere that THN kits with syringes could increase risky behaviour or trigger opioid use relapses. ${ }^{15-17}$ Nevertheless, participation in the THN program has been associated with decreased (rather than increased) high-risk opioid use. ${ }^{29}$

Both patients accepting and refusing THN mentioned thoughts of suicide or not caring whether they overdosed. This is not surprising given the high correlation of opioid use disorder and depression ${ }^{30}$ and previously reported associations between opioid overdoses and suicidal ideation, ${ }^{31}$ further highlighting the need for integration of addiction and mental health care. Although "not being comfortable with injections" has been noted in other populations,${ }^{16}$ our patients, the majority of whom injected drugs, did not mention this barrier often.

Conditional refusals are critical, as they imply that patients might be ready for THN acceptance, although not during that particular ED encounter. Conditional refusals were associated with younger patients and those experiencing homelessness, although neither characteristic was associated with a lower THN acceptance overall. $^{8}$ Among specific reasons for conditional refusals, patients cited "too sick," "in a rush," and "poor timing," all previously unreported in community settings. These reasons may not be surprising in an ED setting where patients are acutely ill and do not present specifically seeking harm reduction services. Some previously identified barriers to accepting THN were not directly mentioned by our study population, notably fear of interacting with police and drug-related stigma. $^{16,19}$

The most common motivator for THN acceptance was helping others, reflected in responses about saving and educating others. This desire is also common in non-ED settings. ${ }^{17,19,20}$ Wanting to protect oneself from an OD or to generally "feel safer" corroborates with a previous quantitative analysis involving our study cohort; those concerned about their own OD risk were more likely to accept THN. ${ }^{8}$ One participant mentioned peer influence, a strong driver of THN 
acceptance elsewhere. ${ }^{21}$ The "feels good" reason mentioned by another is reminiscent and echoes the feeling of personal empowerment cited by other THN research. ${ }^{19,20}$

The THN acceptance reasons, "did not know where to get one," "willing to try," "never had one," "lost other kit," and "supervised injection site crowded," highlight the convenience of ED dispensing. Prior analysis of our study population indicated that $80 \%$ of the patients felt the ED was indeed a convenient setting for THN. ${ }^{8}$ Taken together, these findings further support the concept of the ED as a 24-hour location for patients who might not otherwise have easy THN access.

Preferences for THN dispensing sites have not been previously reported. Even among accepting patients, the supervised injection site of the community was the preferred location. Many factors may play into this preference, including the dislike of hospitals mentioned by one participant. Nevertheless, a lack of feeling respect in the ED, previously noted in another marginalized ED population, ${ }^{32}$ did not appear to play a significant role in patients' THN location preferences or their reasons for refusing THN.

Importantly, our findings may encourage ED THN programs to adopt strategies to enhance uptake. ED staff should gently emphasize true OD risk in a nonjudgmental manner. Second, staff should empower patients by encouraging THN acceptance to help other at-risk peers. For patient convenience, THN needs can be addressed early in the ED stay in parallel with medical management. Even if patients refuse THN in the ED, providers should emphasize the importance of THN kits and encourage patients to discuss it in the community with family, peers, and trusted care providers. The presence of a dedicated nurse, a social worker, or another care provider specially trained in addiction treatment in the ED would likely enhance patient receptivity to both THN and other forms of addiction care and harm reduction.

\section{LIMITATIONS}

Our findings at a single inner-city centre with a high proportion of IDU may be challenging to extrapolate to other settings, but the themes found in our population are congruent with those in non-ED environments. The analysis of open-ended question responses is necessarily limited because of a sampling strategy based on the quantitative design of the survey. Traditional qualitative approaches such as iterative interviewing and theory development could have helped clarify responses, explore additional reasons, and assess theme saturation. Social desirability bias might have occurred in the context of compensation for participation, although the candour of responses suggests that such bias is minimal. A lack of interview recording could have allowed RAs to inject their own words into transcriptions. Interviewer prompting could have directed participants' responses in some cases by providing a quick and easy answer rather than one in an authentic patient voice. Some subgroups, especially those involving patients refusing THN, are small and could draw spurious associations or fail to identify correct ones.

\section{CONCLUSION}

ED patients refusing THN either did not feel at risk of OD or did not feel their ED encounter was the right time or place for THN. Most ED patients accepting THN wanted to save others from an OD.

Acknowledgements: We gratefully acknowledge Alexis Crabtree, MD, MPH, $\mathrm{PhD}$, post-doctoral student at the British Columbia Centre for Disease Control, for her critical revisions of the final manuscript.

Competing interests: None declared.

\section{SUPPLEMENTARY MATERIAL}

To view supplementary material for this article, please visit https://doi.org/10.1017/cem.2018.368

\section{REFERENCES}

1. Special Advisory Committee on the Epidemic of Opioid Overdoses. National report: Apparent opioid-related deaths in Canada (January 2016 to June 2017) Web-based Report. Ottawa: Public Health Agency of Canada; 2017. Available at: https://www.canada.ca/en/public-health/services/publications/ healthy-living/apparent-opioid-related-deaths-report-20162017-december.html.

2. Canadian Institute for Health Information. Opioid-Related Harms in Canada. Ottawa: CIHI; 2017.

3. Wheeler E, Jones TS, Gilbert MK, Davidson PJ, Centers for Disease Control and Prevention (CDC). Opioid overdose prevention programs providing naloxone to laypersons United States, 2014. MMWR Morb Mortal Wkly Rep 2015; 64(23):631-5. 
4. Walley AY, Xuan Z, Hackman HH, et al. Opioid overdose rates and implementation of overdose education and nasal naloxone distribution in Massachusetts: interrupted time series analysis. BM7 2013;346:f174-4.

5. Canadian Centre on Substance Abuse. The availability of take-home naloxone in Canada: CCENDU Bulletin 2016;1-11.

6. Brady JE, DiMaggio CJ, Keyes KM, et al. Emergency department utilization and subsequent prescription drug overdose death. Ann Epidemiol 2015;25(8):613-619.e2.

7. Caudarella A, Dong H, Milloy MJ, et al. Non-fatal overdose as a risk factor for subsequent fatal overdose among people who inject drugs. Drug Alcohol Depend 2016;162:51-5.

8. Kestler A, Buxton J, Meckling G, et al. Factors associated with participation in an emergency department-based takehome naloxone program for at-risk opioid users. Ann Emerg Med 2017;69(3):340-6.

9. Samuels EA, Dwyer K, Mello MJ, et al. Emergency department-based opioid harm reduction: moving physicians from willing to doing. Acad Emerg Med 2016;23(4): 455-65.

10. Samuels E. Emergency department naloxone distribution: a Rhode Island department of health, recovery community, and emergency department partnership to reduce opioid overdose deaths. R I Med 7 2014; 97(10):38-9.

11. Dwyer K, Walley AY, Langlois BK, et al. Opioid education and nasal naloxone rescue kits in the emergency department. West 7 Emerg Med 2015;16(3):381-4.

12. Drainoni ML, Koppelman EA, Feldman JA, et al. Why is it so hard to implement change? A qualitative examination of barriers and facilitators to distribution of naloxone for overdose prevention in a safety net environment. BMC Res Notes 2016;9(1):465.

13. Ellison J, Walley AY, Feldman JA, et al. Identifying patients for overdose prevention with ICD-9 classification in the emergency department, Massachusetts, 2013-2014. Public Health Rep 2016;131(5):671-5.

14. Lacroix L, Thurgur L, Orkin AM, Perry JJ, Stiell IG. Emergency physicians' attitudes and perceived barriers to the implementation of take-home naloxone programs in Canadian emergency departments. CFEM 2018;20(1):46-52.

15. Sondhi A, Ryan G, Day E. Stakeholder perceptions and operational barriers in the training and distribution of takehome naloxone within prisons in England. Harm Reduct 7 2016;13:5.

16. Black L, Connolly I, Getty M, et al; Addiction SURG. Poor implementation of naloxone needs to be better understood in order to save lives. Addiction 2017;112(5):911-2.

17. Wright N, Oldham N, Francis K, Jones L. Homeless drug users' awareness and risk perception of peer "take home naloxone" use-a qualitative study. Subst Abuse Treat Prev Policy 2006;1:28.
18. Lagu T, Anderson BJ, Stein M. Overdoses among friends: drug users are willing to administer naloxone to others. 7 Subst Abuse Treat 2006;30(2):129-33.

19. Tzemis D, Al-Qutub D, Amlani A, et al. A quantitative and qualitative evaluation of the British Columbia Take Home Naloxone program. CMA7 Open 2014;2(3):E153-61.

20. Wagner KD, Davidson PJ, Iverson E, et al. "I felt like a superhero": the experience of responding to drug overdose among individuals trained in overdose prevention. Int 7 Drug Policy 2014;25(1):157-65.

21. Wagner KD, Iverson E, Wong CF, et al. Personal social network factors associated with overdose prevention training participation. Subst Use Misuse 2013;48(1-2):21-30.

22. Lingard L, Albert M, Levinson $W$. Grounded theory, mixed methods, and action research. BMF 2008;337:a567-7.

23. O'Brien BC, Harris IB, Beckman TJ, Reed DA, Cook DA. Standards for reporting qualitative research: a synthesis of recommendations. Acad Med 2014;89(9):1245-51.

24. Yvonne Feilzer M. Doing Mixed Methods Research Pragmatically: Implications for the Rediscovery of Pragmatism as a Research Paradigm. 7 Mixed Methods Res 2009;4:6-16.

25. Winit-Watjana $W$. Research philosophy in pharmacy practice: necessity and relevance. Int 7 Pharm Pract 2016; 24(6):428-36.

26. Kerr T. North America's first supervised injection site opens in Vancouver. Can HIV AIDS Policy Law Rev 2003; 8(3):24-5.

27. Campbell JL, Quincy C, Osserman J, Pedersen OK. Coding in-depth semistructured interviews: problems of unitization and intercoder reliability and agreement. Sociol Methods Res 2013;42:294-320.

28. Bohnert AS, Valenstein M, Bair MJ, et al. Association between opioid prescribing patterns and opioid overdoserelated deaths. FAMA 2011;305(13):1315-21.

29. McDonald R, Strang J. Are take-home naloxone programmes effective? Systematic review utilizing application of the Bradford Hill criteria. Addiction 2016;111(7):1177-87.

30. Goldner EM, Lusted A, Roerecke M, Rehm J, Fischer B. Prevalence of Axis-1 psychiatric (with focus on depression and anxiety) disorder and symptomatology among non-medical prescription opioid users in substance use treatment: systematic review and meta-analyses. Addict Behav 2014;39(3):520-31.

31. Richer I, Bertrand K, Vandermeerschen J, Roy E. A prospective cohort study of non-fatal accidental overdose among street youth: the link with suicidal ideation. Drug Alcobol Rev 2013;32(4):398-404.

32. McCormack RP, Hoffman LF, Norman M, Goldfrank LR, Norman EM. Voices of homeless alcoholics who frequent Bellevue Hospital: a qualitative study. Ann Emerg Med 2015;65(2):178-86.e6. 